\title{
Communications.
}

\section{Diagnose provisoire d'un Mecinus nouveau [CoL. Curculionidae]}

par E. Abeille de Perrin.

Mecinus erythrocerus, n. sp. - Niger, nitidus, elytris striatis, antennis, tibiis tarsisque laete rufis. - Long. 2,כ̆ mill.

Noir brillant, sauf les antennes, tibias et tarses qui sont d'un rouge tranchant. Tellement voisin du collaris par l'aspect général et les proportions du corps, ainsi que par la couleur, que je me contenterai d'en donner les différences : taille plus petite, couleur nette des antennes, tibias et tarses, points des stries plus serrés, interstries plus convexes, corselet plus rudement sculpté, l'ensemble des points moins régulier; forme générale plus massive, corselet plus étroit en avant.

Découvert au nombre de deux individus par M. Hustache dans le Jura français, aux environs de Dôle.

\section{Sur une particularité des joues chez les mâles des Oenas et de deux Lydus [Col. Heteromera]}

par L. BEDEL.

On sait que les mâles des Oenas se reconnaissent à leur $6^{\text {e }}$ sternite (segment anal) terminé par une petite entaille et souvent aussi à leurs antennes épaisses ou mème au $\mathbf{1}^{\mathrm{er}}$ article de leurs tarses intermédiaires verticalement dilaté; mais, dans la pratique, la distinction des sexes ne va pas toujours sans quelque difficulté.

Il existe heureusement un autre caractère, inaperçu jusqu'ici, qui permet de reconnaitre les mâles à première vue : c'est une excavation à fond lisse, qui longe le bord inférieur de l'œil et occupe une grande partie de la surface des joues. Il ne semble pas que cette excavation puisse servir de " sillon antennaire "; elle constitue, en tout cas, un caractère sexuel secondaire invariable et commun à toutes les espèces du genre Oenas Latr.

Une semblable excavation des joues se retrouve chez les mâles de deux Lydus d'Orient, les $L$. humeralis Gyll. et $L$. tarsalis Ab. (ce- 


\section{$2 \mathrm{BHL}$ Biodiversity Heritage Library}

1910. "Diagnose provisoire d'un Mecinus nouveau." Bulletin de la Société entomologique de France 1910, 83-83. https://doi.org/10.5962/bhl.part.4663.

View This Item Online: https://www.biodiversitylibrary.org/item/38239

DOI: https://doi.org/10.5962/bhl.part.4663

Permalink: https://www.biodiversitylibrary.org/partpdf/4663

\section{Holding Institution}

Smithsonian Libraries

\section{Sponsored by}

Smithsonian

\section{Copyright \& Reuse}

Copyright Status: NOT_IN_COPYRIGHT

This document was created from content at the Biodiversity Heritage Library, the world's largest open access digital library for biodiversity literature and archives. Visit BHL at https://www.biodiversitylibrary.org. 